\title{
CHARACTERIZATION STUDY FOR REDUCING CORROSION \& FRACTURE PROBLEM OF RAIL TRACK BY FABRICATION OF COMPOSITE MATERIAL
}

\author{
AMIT TIWARI ${ }^{1} \&$ DR. NEERAJ KUMAR ${ }^{2}$ \\ ${ }^{1}$ Scholar, Department of Mechanical Engineering, Suresh GyanVihar University, Jaipur, Rajasthan, India \\ ${ }^{2}$ Professor \& Head of Department, Department of Mechanical Engineering, Suresh GyanVihar University, \\ Jaipur, Rajasthan, India
}

\section{ABSTRACT}

The corrosion behavior of steels with $\mathrm{Cu}, \mathrm{Mn} . \mathrm{Cr}, \mathrm{Ni}$ and Si alloying addition was studied by weight loss measurement. A relative comparison between all three compositions have C-Mn has more effectively strong and corrosion resistance then another two comparison. Eutectiod steel were traditionally used as rail the aim of the present study was to evaluate order to minimize fracture and corrosion problem on railway track we selected three compositions and performed work over them. The results are optimized on Minitab Statistical Software where ANOVA techniques was used to find out one best composition out of remaining anothertwo composition of steel.

KEYWORDS: Corrosion, Rail Track \& Fabrication

Received: Jun 06, 2020; Accepted: Jun 26, 2020; Published: Jul 16, 2020; Paper Id.: IJMPERDJUN2020343

\section{INTRODUCTION}

Composite materials are important engineering aterial because of their unique mechanical properties. MMC's are one of the widely known composite due to their superior properties like high strength, hardness, stiffness, wear and corrosion resistance. These properties used in all engineering applications such as automobile, aerospace, railway's etc [5]. The railways sector very carefully manufacturing rail tracks because many peoples travel in daily life so it is more important to manufacturing good material for track. Now a days in modern technology the composite material play a very important role for manufacturing material with enhance properties.

Railways were originally uniquely identified with the material of their initial construction and now are technically identified by their characteristic contact of steel wheel on steel rail $[9,12]$. Steel used for railway rails are generally eutectoid steel with a fully pearlitic microstructure because pearlite provide optimum combination of strength and ductility. Fracture occurs frequently in rail and thermite welded joints, which intimidates the security and reliability of railway services. Railway in low temperature region make the problem of brittle fracture in rails even worse. Railway track are subjected to fluctuant stresses and impact load as the train wheel pass along them. Thermite welding joints are critical spot in rails due to their inherent casting nature and initial defects. Corrosion problem in railway track is also a major problem now a days. [14] Moreover sudden failures of rails is a major safety concern. In order to minimize corrosion problem in track steel manufacturing industries contionus develop material but this is not enough for reducing so we need to develop composite material for enhance the properties of steel. $[18,19]$ For many research also found that toilet discharge on the rail track and collected moisture from the atmosphere on the rail track cause intended localizes corrosion under the liners. 


\section{PROBLEM IDENTIFIED}

During survey we found that corrosion properties is highly responsible to reduced properties of rail steel and fracture problem comes when steel comes to contact low temperature zone due to this steel shrinking more and material get slowly reducing their strength at low temperature so we developed or identified such material have resist from corrosion and fracture issues on rail steel.

\section{REQUIREMENT OF GOOD RAILWAY TRACK}

A permanent way or track should provide a comfortable and safe ride at the maximum permissible speed with minimum maintenance cost to achieve this objective a sound permanent way should have the following characteristics:-

- The gauge should be correct and uniform.

- The track should be resilient and elastic in order to absorb the shock and vibrations of running train.

- The track should have good lateral strength so that it can be maintain its stability despite variation in temperature and other such factors.

- The track should have such a easy replacement and renewal of the various track component.

- The track should have such a structure that one only is its initial cost low but also its maintenance cost is minimum.

\section{FORCES ACTING ON THE TRACK}

- Lateral force due to movement of live loads, eccentric vertical loading, shunting of locomotive, etc..

- Contact stress due to wheel and rail contact.

- Stresses due to surface defect such as flat spots on wheel etc.

- Longitudinal force due to tractive effort and braking force, thermal forces etc.

- Vertical load consisting of dead loads, dynamic augments of loads including the effect of speed, the hammer blow effect, the inertia of reciprocating masses etc.

\section{MATERIAL USED FOR MANUFACTURING RAILWAY TRACK}

Rail steel commonly used carbon manganese steel with most pearlitic microstructure. The method used to make the steel for rails very between the oxygen furnace and more modern electric arc furnace with vacuum degassing to remove hydrogen and oxygen and other gases from the molten steel form. The chemical composition tensile strength and hardness values different with the different grades of rails [14]. In Estonia the chemical composition of grade R350 HT. There are many composition developed for reducing corrosion problem in which such material are $\mathrm{Cu}, \mathrm{Cr}$, $\mathrm{Ni}$ and $\mathrm{Si}$. Some experiment was conducted with different composition like $\mathrm{C}-\mathrm{Mn}, \mathrm{Cu}-\mathrm{Mu}, \mathrm{Cr}, \mathrm{Mn}$ where tensile properties have been understood by considering microstructural behavior of material and fracture surface features. In railway sector three grade have minimum tensile strength of 700, 800 and 1080-1200 MPa respectively. This grades are applied in service depending on the requirements of traffic density and axial load. 
At current senerio network consisting of rails of tensile strength of 800 grade which are known as grade 800 rails. The $800 \mathrm{MPa}$ rail is a rail grade designed for higher wear resistance than the normal $700 \mathrm{MPa}$ rail. Therefore the standard $60 \mathrm{~kg} \mathrm{~m}$ as well as the $52 \mathrm{~kg} \mathrm{~m}$ rails are now rolled to rails of tensile strength of $800 \mathrm{MPa}$. As per the Indian railway permanent way specifications at $60 \mathrm{~kg} \mathrm{~m}$ rail section should be able to withstand 800 gross metric ton of load before it fails. Steel plates of the four new composition like. $\mathrm{Cu}-\mathrm{Si}, \mathrm{Cu}-\mathrm{Ni}, \mathrm{Cr}-\mathrm{Cu}-\mathrm{Ni}, \mathrm{Cr}-\mathrm{Cu}-\mathrm{Ni}-\mathrm{Si}$ where passed at research and development centre for Iron and Steel SAIL, Ranchi following a similar procedure as the rolling of normal rail steel.

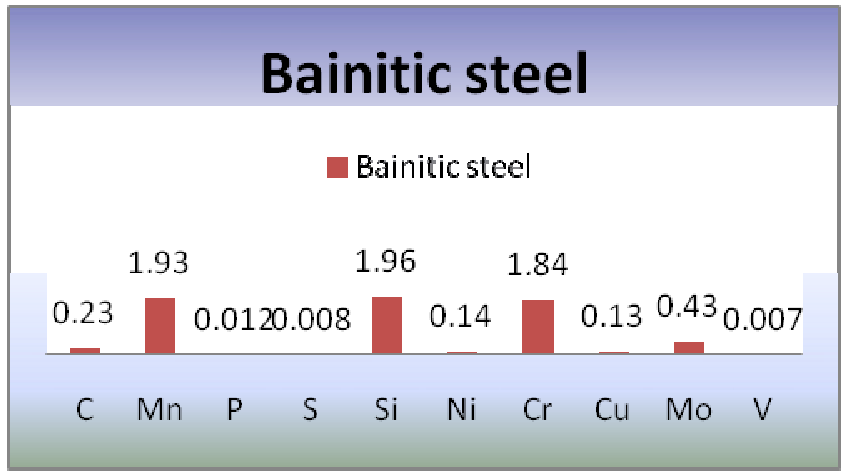

Chart 1: Compositions of Bainitic Steel for the Rail Steels in Percentage by Weight.

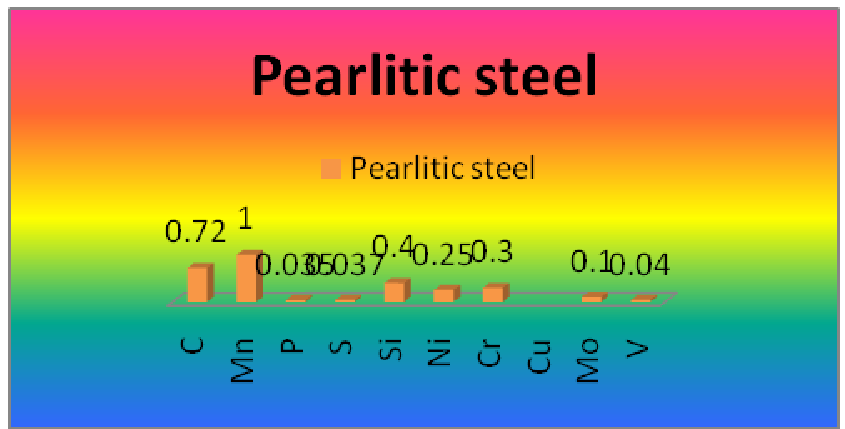

Chart 2: Compositions of Pearlitic Steel for the Rail Steels in Percentage by Weight.

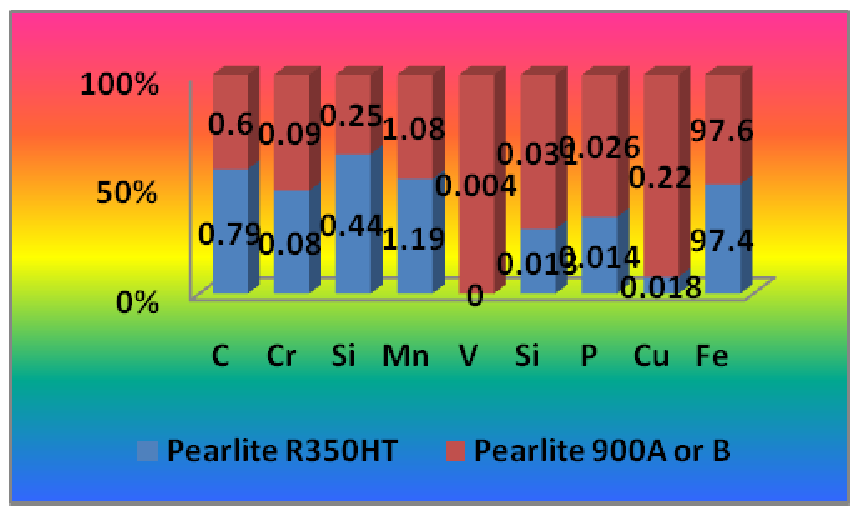

Chart 3: Compositions of Pearlitic (R 350HT, 900 A or B) Steel for the Rail Steels in Percentage by Weight. 


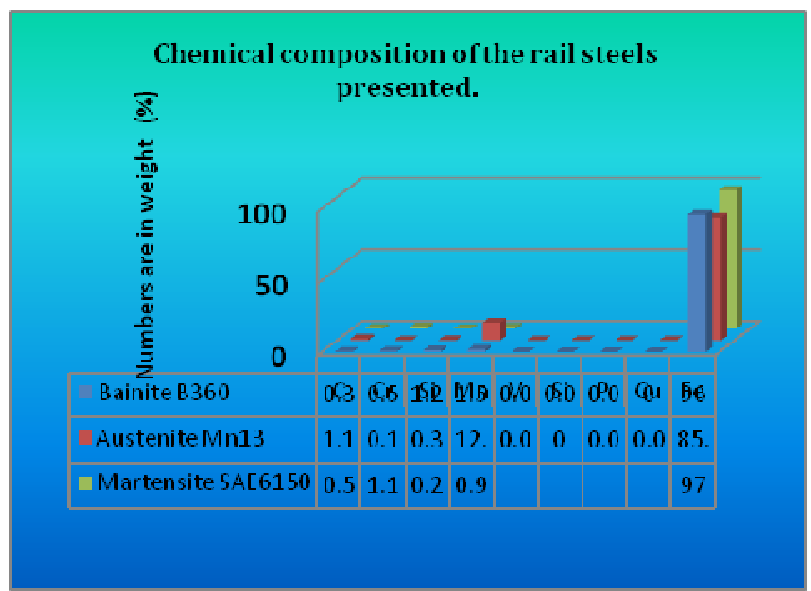

Chart 4: Compositions of (Bainite B360, Austenite Mn13, Martensite SAE 150)

\section{RAIL MANUFACTURING}

Steel for the Rail Steels in Percentage by Weight.

The Steel used for the manufacturing of rails is made by the open hearth or duplex process and should not have a wide variation in tis chemical composition. There are essentially four stages of rail manufacturing.

- Steel manufacturing process using a oxygen /electric arc furnace, including argin rising and degassing.

- Continuous casting of blooms.

- Rail rolling process including controlled cooled

- Rail finishing including eddy current testing, ultrasonic testing and finishing work.

\section{DESIRABLE PROPERTIES OF STEEL RAIL ARE AS FOLLOWS}

Table 1: Chemical Composition

\begin{tabular}{|c|c|c|c|c|c|c|c|}
\hline Grade & $\mathbf{C}$ & Mn & Si & S & P (max.) & Al (max.) & $\begin{array}{c}\text { Liquid } \\
\text { Hydrogen }\end{array}$ \\
\hline 800 & $0.6-08$ & $0.8-1.3$ & $1.3-0.5$ & 0.035 & 0.035 & 0.02 & 3.00 \\
\hline
\end{tabular}

Table 2: Mechanical Properties

\begin{tabular}{|c|c|c|}
\hline UTS (MPa; min.) & $\begin{array}{c}\text { Elongation \% on Gauge } \\
\text { Length }=\mathbf{5 . 6 5} / \mathbf{S}^{*} \text { (min.) }\end{array}$ & $\begin{array}{c}\text { Running Surface } \\
\text { Hardness }\end{array}$ \\
\hline 880 & 10.0 & Min. 260† \\
\hline
\end{tabular}

Second Quality Rail

Table 3: The Chemical Composition of Second Quality Rail are as Follows

\begin{tabular}{|l|c|c|c|}
\multicolumn{1}{|c|}{ Element } & \% in Carbon Steel & \% in Medium Manganese Steel & $\begin{array}{c}\text { Revised \% in Medium } \\
\text { Manganese Steel }\end{array}$ \\
\hline Carbon & $0.50-0.70$ & $0.40-0.60$ & $0.40-0.65$ \\
\hline Manganese & $0.60-0.95$ & $0.90-1.45$ & $0.85-1.45$ \\
\hline Sulphur & 0.06 max. & 0.06 max. & 0.06 max \\
\hline Phosphorus & 0.06 max. & 0.06 max. & 0.06 max. \\
\hline Silicon & $0.03-0.30$ & $0.03-0.30$ & $0.03-0.30$ \\
\hline
\end{tabular}

\section{90 UTS Rails}

Indian Railways has mostly been used medium manganese rail with an ultimate tensile strength UTS of $72 \mathrm{~kg} / \mathrm{m}^{2}$ 
manufactured by Bhilai steel plant. These rail have the following main advantages are the service life of 90 UTS rails is about 50\% more than of conventional medium manganese 72 UTS rail. $[16,18]$ The 90 UTS rail are more resilient against wear and have a hardness of about $270 \mathrm{BHN}$ (Brinell hardness number) as against that of $220 \mathrm{BHN}$ of medium manganese rail with 72 UTS.

\section{HEAD HARDENED RAILS}

These are rail with heads that have been hardened by passing them through a thermal treatment plant. The head is hardened for a depth of about $12 \mathrm{~mm}$ from the surface. Head Hardened rails have a longer service life that extends upto 2-3 times more compared to as ordinary medium manganese rails.

Table 4: The chemical composition of Head Hardened Steel (Grade 1080) is Given Below

\begin{tabular}{|l|c|c|c|c|c|}
\hline \multicolumn{1}{|c|}{ Item } & Carbon & Manganese & Silicon & Sulphur & Phosphorus \\
\hline Limit of Values & $0.72-0.82$ & $0.75-1.05$ & $0.05-0.30$ & 0.035 max. & 0.035 max. \\
\hline
\end{tabular}

\section{WEARING OF RAIL}

Due to the passing of moving load and friction between the rail and the wheel the rail head gets worn out in the source of service. The impact of moving load the effect of the force of acceleration, deceleration and braking of wheels. The abrasion due to rail wheel interaction. The effect of weather conditions such as change of temperature, snow and rain this loss of weight of rail section should not be such that the stresses exceed their permissible values.

\section{IDENTIFIED SOME TYPES OF WEAR ON RAIL ARE AS FOLLOWS}

A rail may face wear and tear in the following position

- On top of the rail head (Vertical Wear)

- On the sides of the rail head (Lateral Wear)

- On the end of the rail (Battering of rail ends)

- Wear is more prominent at some special location of the track. These location are normally the following.

- On sharp curves, due to centrifugal forces.

- On approaches to railway stations possible due to acceleration and deceleration.

\section{MATERIAL AND METHODS}

There are so many material for reducing corrosion and fracture issue in rail track. Apart from the general corrosion, crevice corrosion between the linear and rail foot is a major source for localized corrosion. The rail foot passes the thinnest cross section and id corroded due to the accumulation of corrosive media emanating from various sources. Apart from the contaminants from the atmosphere the discharge from the open lavatories of the Indian passenger coaches are great concern. In order to minimize rail corrosion problem faced by Indian railways three new rail steels were design based on a detailed study of literature review of many papers after that three material is used for reducing the corrosion issues in rail steel. The aim of the current study was to test these three composition and to check in which composition that would resist corrosion better than traditional steel in Indian culture. 
Table 5: Sample of Chemical Composition of Steel in (wt \%)

\begin{tabular}{|l|c|c|c|c|c|c|c|c|c|}
\hline Sample & C & Mn & Cu & Mo & Cr & Ni & Si & S & P \\
\hline C-Mn & 0.69 & 1.00 & - & - & - & - & 0.19 & 0.010 & 0.022 \\
\hline $\mathrm{Cr}-\mathrm{Mn}$ & 0.70 & 1.08 & - & - & 0.84 & - & 0.69 & 0.020 & 0.015 \\
\hline $\mathrm{Cu}-\mathrm{Ni}$ & 0.65 & 1.02 & 0.46 & - & - & 0.22 & 0.45 & 0.022 & 0.031 \\
\hline
\end{tabular}

The corrosion rate was calculated from the weight loss measurements by using the following relationship.

Corrosion rate $(\mathrm{mm} / \mathrm{y})=(\mathrm{K} \times \mathrm{W}) /(\mathrm{A} \times \mathrm{T} \times \mathrm{D})$

Where $\mathrm{K}=$ Constant, $8.76 \times 10^{\wedge} 4$, for corrosion rate calculation in millimeters per year, $\mathrm{W}=$ mass loss in $\mathrm{g}, \mathrm{A}=$ area in $\mathrm{cm}^{2}, \mathrm{~T}=$ Time of exposure in hours, $\mathrm{D}=$ Density in $\mathrm{g} / \mathrm{cm}^{3}$.

Table 6: Weight Loss and Corrosion rate after 55 Days of Wet Dry Salt Fog Exposure

\begin{tabular}{|l|c|c|}
\hline & \multicolumn{2}{|c|}{ Wet Dry Salt Fog Exposure } \\
\hline \multicolumn{1}{|c|}{ Sample } & & Weight Loss $\left(\mathbf{g} / \mathbf{c m}^{\mathbf{3}}\right)$ \\
\hline $\mathrm{C}-\mathrm{Mn}$ & 0.072 & Corrosion Rate $(\mathbf{m m} / \mathbf{y})$ \\
\hline $\mathrm{Cr}-\mathrm{Mn}$ & 0.086 & 0.71 \\
\hline $\mathrm{Cu}-\mathrm{Ni}$ & 0.097 & 0.79 \\
\hline
\end{tabular}

\section{RESULTS}

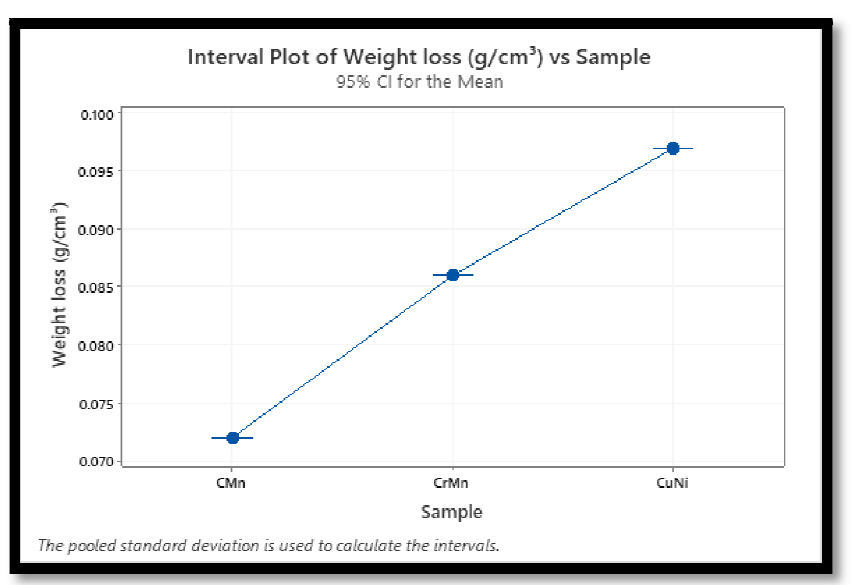

Figure 1: The figure Shown About the Composition C-Mn was Less Weight Material as Compared to Another after 55 Days of Experiment and more Efficient to Resist Corrosion Issues on Track where $\mathrm{Cu}-\mathrm{Ni}$ Composition was High Weight Loss Rate which is not Demanded for Application. 


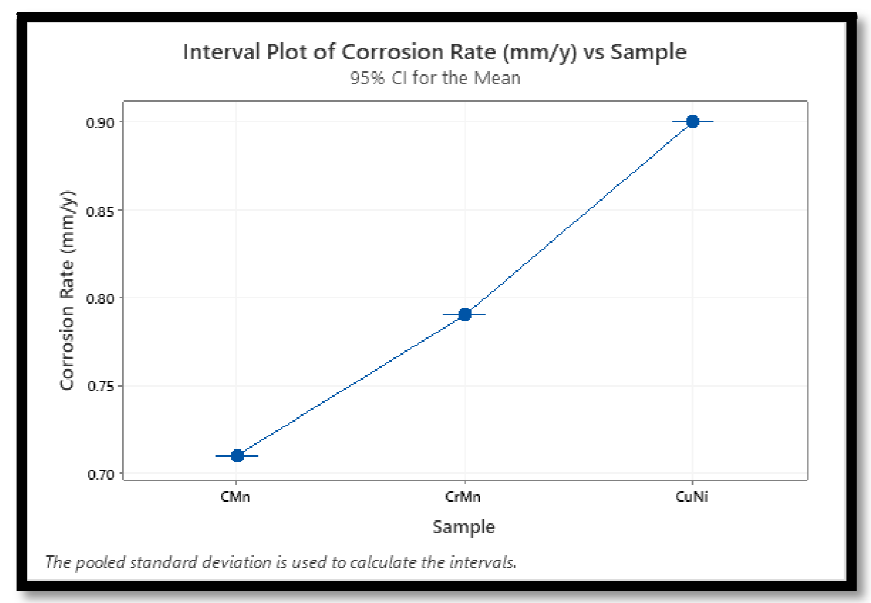

Figure 2: The figure shown about the Composition C-Mn was Less Corrosion Rate as Compared to another after 55 Days of Experiment and more Efficient to Resist Corrosion Issues on Track where $\mathrm{Cu}$-Ni Composition was High Corrosion Rate which is not Required.

Table 7: Sample Data Hardness and Tensile Properties of Steels

\begin{tabular}{|l|c|c|c|c|c|}
\hline Sample & Hardness HRD & $\mathbf{0 . 2} \%$ YS, MPa & UTS, MPa & Elongation \% & Reductions in Area \% \\
\hline $\mathrm{C}-\mathrm{Mn}$ & 52.4 & 460 & 898 & 13 & 23 \\
\hline $\mathrm{Cr}-\mathrm{Mn}$ & 49.06 & 572 & 625 & 11 & 48 \\
\hline $\mathrm{Cu}-\mathrm{Ni}$ & 44.2 & 501 & 820 & 12.5 & 52 \\
\hline
\end{tabular}

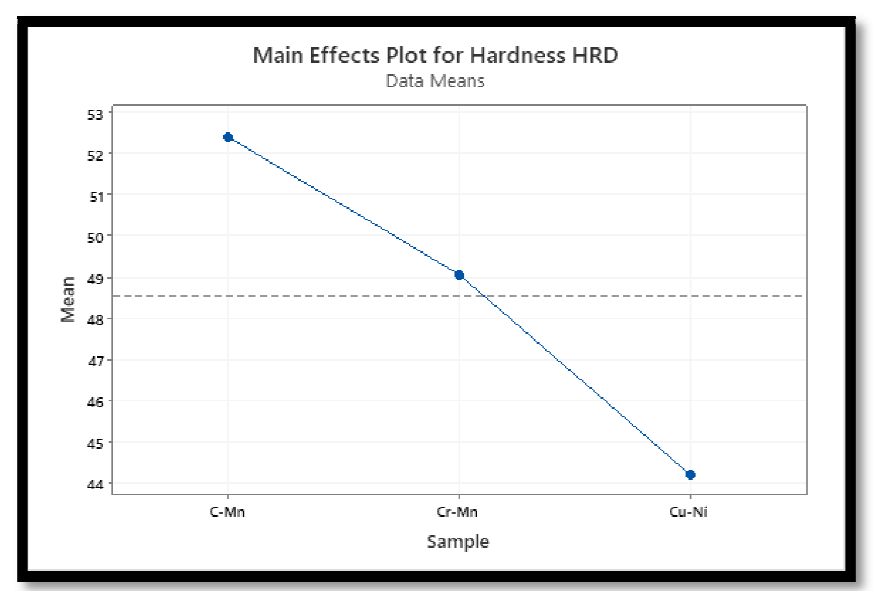

Figure 3: The figure shown about the Composition C-Mn was High Material Hardness Rate as Compared to another Two Composition and more Efficient to Reduce Fracture Issues on Track where $\mathrm{Cu}-\mathrm{Ni}$ Composition was Hardness Rate which is not Demanded for Application. 


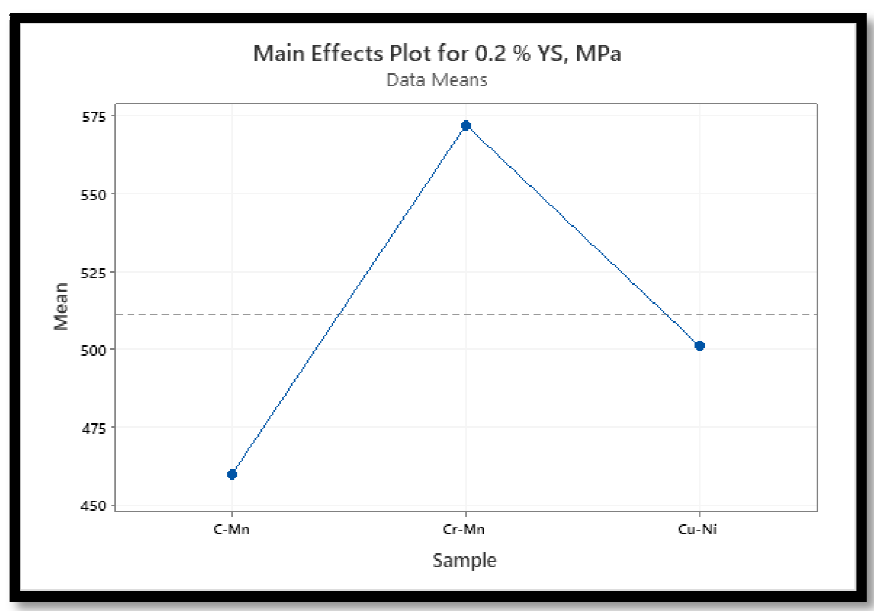

Figure 4: The figure shown about the Composition C-Mn was

Low Yield Strength Rate as Compared to another Two Composition and have a more Capacity to Bearing High Stresses on Track.

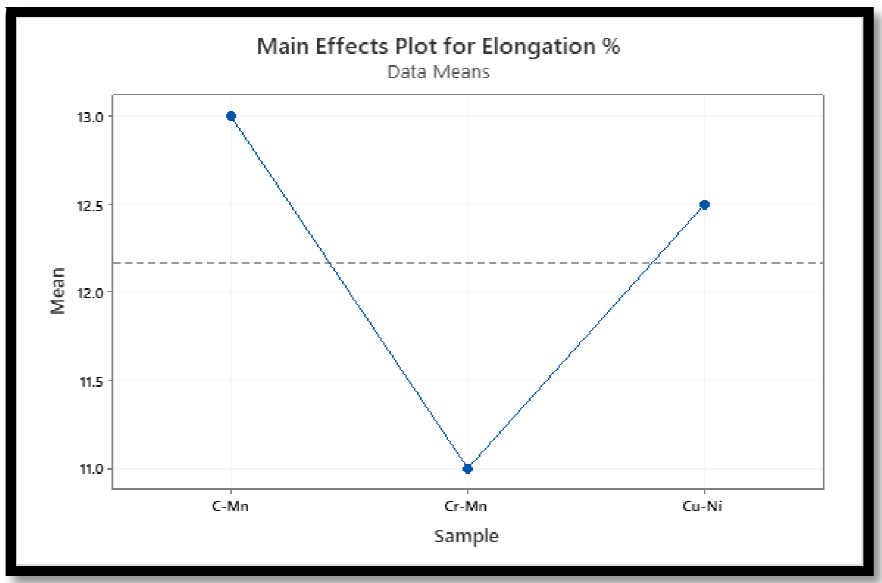

Figure 5: The figure shown about the Composition C-Mn was High Elongation Rate as Compared to another Two Composition.

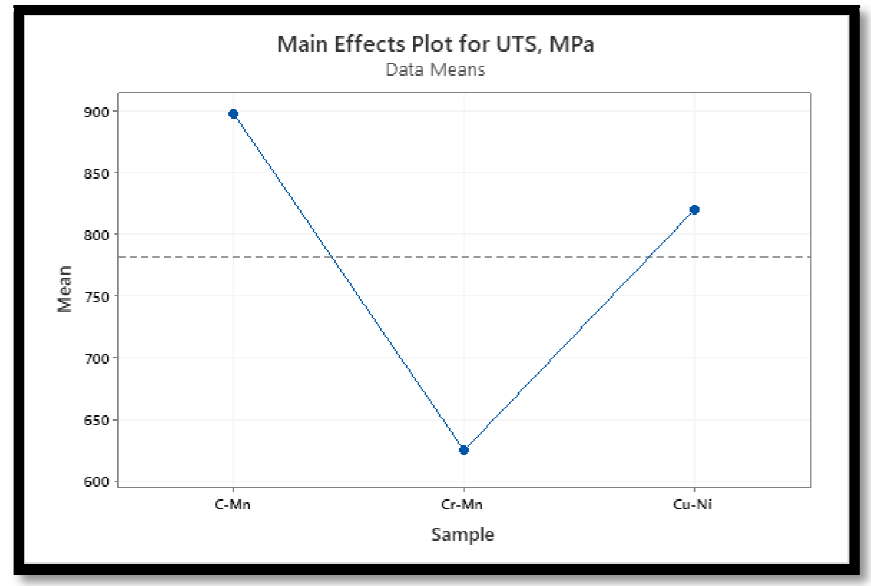

Figure 6: The figure shown about the Composition C-Mn was High Ultimate Strength Rate as Compared to another Two Composition and have a more Capacity to Bearing High Stresses on Track without any Failures. 


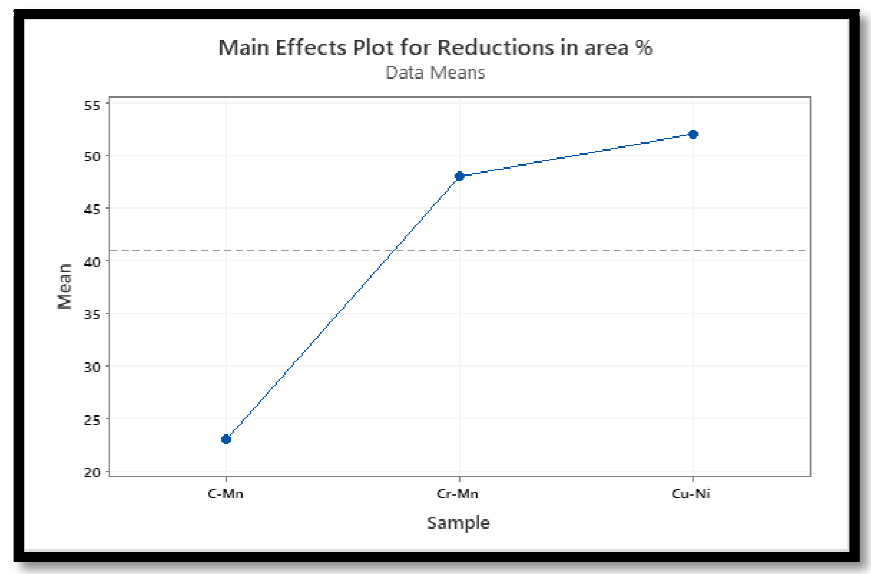

Figure 7: The figure shown about the Composition C-Mn was

Low Material Reduction rate as Compared to another Two Composition and have a more Efficient to Resist Corrosion and Fracture Issues on Track.

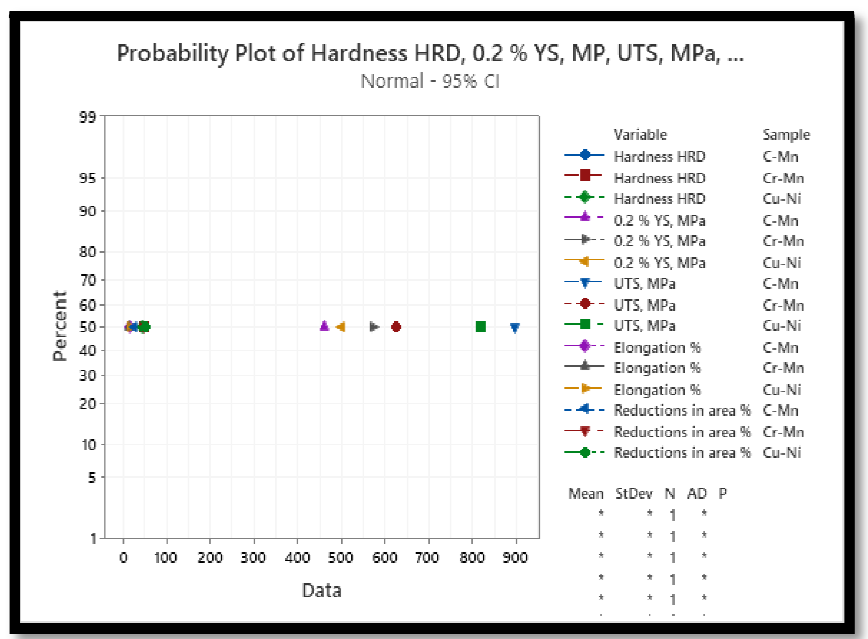

Figure 8: The figure shown about the Probability Plot of Hardness, Yield Strength, Ultimate Tensile Strength as Respect to all Three Samples which so Clearly that the Material C-Mn is more Effectively Work as Compare to another Two Materials.

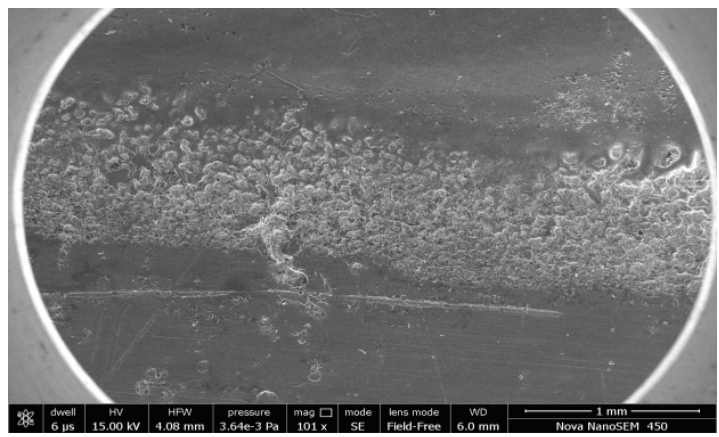

Figure 9: The figure shown SEM Test Structure of the Composition C-Mn was Low Corrosion Rate. 


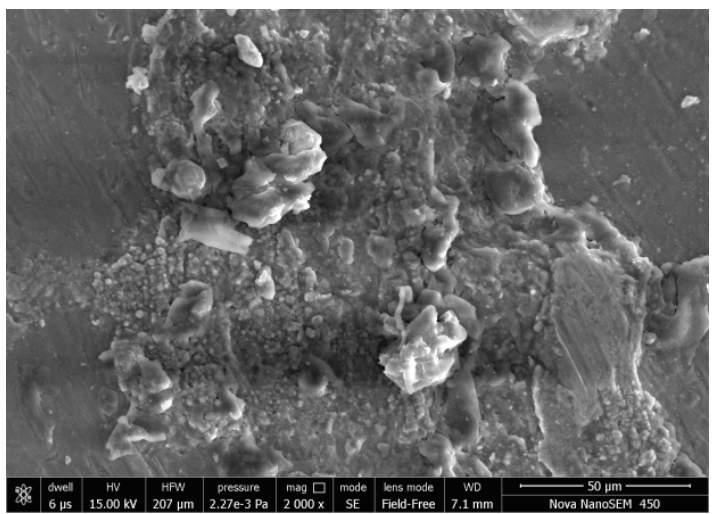

Figure 10: The figure shown SEM test Structure of the Composition Cr-Mn was Moderate Corrosion Rate.

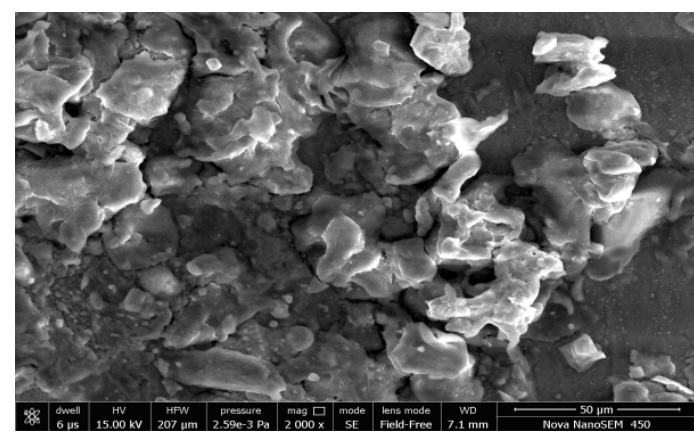

Figure 11: The figure shown SEM Test Structure of the Composition Cu-Ni was High Corrosion Rate.

\section{CONCLUSIONS}

Rail steel a usually a low alloy steel with some C,Cr, Mn, Cu,Ni,V,Mo etc. with minor addition of other elements. Elements such as C, Cr, V, Mo, Mnetc are added for hardening, corrosion resistance and strengthening. Larger addition of $\mathrm{Cr}$ and $\mathrm{Ni}$ considerably increase the resistance to atmospheric corrosion and or corrosion in aqueous system. However this would considerably increase the cost of rail and probably have limited to no corrosion reduction benefits because the main factor that accelerates the rail base corrosion is the return current. So we need to developed such types of material who prevent from the corrosion and fracture problem of rail steel.

\section{ACKNOWLEDGEMENT}

The authors would like to thanks the Suresh GyanVihar University, Jaipur for help to conducting research work on this topic in department of mechanical engineering. I would also like to thanks my coauthor Dr. Neeraj Kumar sir their guidance and valuable suggestion to improve the quality of research paper.

\section{REFERENCES}

1. T.Ishikawa, A Maeda, K. Kandori, A. Tahara, characterization of rust on Fe-Cr, Fe-Ni and Fe-Cu binary alloys by Fourier transform infrared and N2 adsorption, corrosion 62 (2006) 559-567.

2. Panda, B. Balasubramaniam. R and Dwivedi. G. and Mahapatra.S. Corrosion of novel rail steels in $3.5 \%$ NaCl Solution. Trans. Indian Inst. Met. 2008.61.177-181. 
3. A.M Elwazri. P. Wanjara and S.Yue. "The effect of microstructural characterisitics of pearlite on the mechanical properties of hypereutectoid steel." Mater.Sci.Eng. A.Vol. 404.no.1,pp. 91-98, 2005.

4. Cicek, V. O. L. K. A. N., and M. E. H. M. E. T. Ozdemir."Characterization Studies of Aqueous Immersion Solutions of Novel Environmentally Friendly Organometallic Corrosion Inhibitors used to Cure Aluminum 2024, 6061, AND 7075 Alloys Substrates in Corrosive Media." International J. of General Engineering and Technology (IJGET), 2 (2), 1 16 (2013).

5. A.P. Moon, S. Sangal, S. Layek, S. Giribaskar and K. Mondal, Corrosion behavior of high strength Bainitic Rail steel," Metall. Mater. Trans A.Vol 46. No 4 pp. $1500-1518,2015$.

6. Baotong. L and Xiluin"Predicting fatigue crack growth rates and threshold at low temperature, Material science and Engineering, A148: 179-188.

7. Stephens, RI. Chung, JH. Glinka. G. "Low temperature fatigue behavior of steels-A Review. "SAE Technical Paper 790517, 1979, doi: 104271/790517.

8. Esveld, C, kok, AWM interaction between moving vehicle and Railway track at high speed. Rail Engineering International 27, 3, 14-16.

9. Misawa T. Asami K. Hashimoto K and Shimodria S. Corrosion Sci II 35.

10. Yadav. A.P. Nishikata A and Tsuru, CorrosSci 43 (2001) 429.

11. Jones D.A. Principles and Preventions of corrosion, Prentice-Hall, NJ (1996) P. 86

12. Kwon S. Shinoda. K. Suzuki S and Waseda Y. CorrosSci 49 (2000) 1513.

13. Landolt, D. Corrosion and surface chemistry of metal. EPFL Press (2007) ISBN 0849382335, P. 312.320.

14. Bardal, E. Corrosion and protection, Springer-Verlag London limited (2004) ISBN 1852337583, P. 110-120.

15. Ilamparithi, A., S. Ponnusamy, and A. Selvaraj."Investigation on N-Formyl Piperidin-4-Ones as Corrosion Inhibitors for Carbon Steel in Acid Medium." Int. J. Appl. Nat. Sci., 3 (2), 6380 (2014).

16. Krunger. J. Passivity In corrosion fundamentals, Testing and protection, ASM Handbook, ASM International materials Park 2003, Vol. 13 A pp. 61- 67.

17. Uhlig. H.H. Corrosion and Corrosion control, Wiley \& Sons. New York, 1971, $2^{\text {nd }}$ edition p.92.

18. Saber, D., KhAbd El-Aziz, and A. Fathy."Corrosion behavior of copper-alumina nanocomposites in different corrosive media." Int. J. Mech. Eng 5 (2016): 1-10.

19. Alloy development of corrosion resistant rail steel, R. Balasubramaniam, B. Pande, and R.K. Rathi, current science, Volume 100 No 1, 10Janurary 2011.

20. Corrosion prevention by Applied coatings on aluminum alloys in corrosion environment, Jingyi Yueand Yan Cao, International Journal of electrochemical science, Volume No 10, 2015.

21. Study of corrosion behavior of pearlitic rail steel, S. Samal and S.K. Mitra, Journals of minerals and materials characterization and engineering, Volume 10,No 7, 2011.

22. Viswanathan, R., et al. "Improving Corrosion Resistance of Magnesium Alloy for Aerospace Applications." International Journal of Mechanical and Production Engineering Research and Development 9.3 (2019): 769-774.

23. On the corrosion behavior of novel high carbon rail steel in simulation cyclic wet-dry salt fog conditions, Bijayani Panda, and Gopalm Dwivedi, Corrosion science, 18 march 2008. 
24. Formation of corrosion protective rust on steel exposed to the atmosphere, H. Nagano and M. Yamashita, Material and Environment lab Inc. 2013.

\section{AUTHOR'S PROFILE}

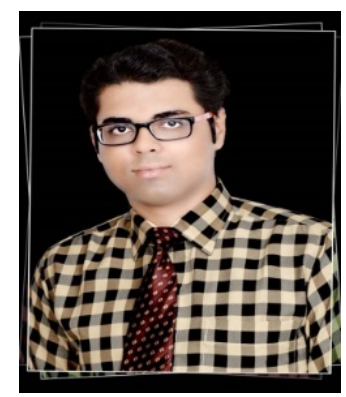

Amit Tiwari received his M.Tech degree in Production Engineering from Pacific University, Udaipur Rajasthan India. He published 4 books and45 research papersinclusive 3 Scopus. He currently pursuing Ph.D in Department of Mechanical Engineering at Suresh GyanVihar University, Jaipur Rajasthan India.

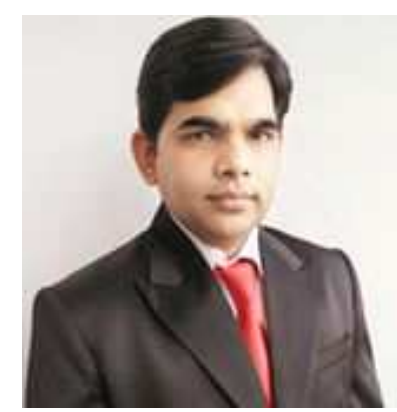

Dr.Neeraj Kumar HoldPh.D(Mechanical), M.Tech (Manufacturing System Engineering) \&B.E (Mechanical) with 14years experience inclusive of 13 year as ENGINEERING TEACHING FACULTY. Published four books and more than 100 research papersinclusive 25 Scopus. Presently associate with SURESH GYAN VIHAR UNIVERSITY, JAIPUR as a Professor \& Head of Mechanical Department. 